Voix et Images

voixetimages

\title{
Un patrimoine culturel de premier ordre
}

\section{Zilá Bernd}

Volume 30, numéro 3 (90), printemps 2005

La littérature anglo-québécoise

URI : https://id.erudit.org/iderudit/011852ar

DOI : https://doi.org/10.7202/011852ar

Aller au sommaire du numéro

\section{Éditeur(s)}

Université du Québec à Montréal

ISSN

0318-9201 (imprimé)

1705-933X (numérique)

Découvrir la revue

Citer ce document

Bernd, Z. (2005). Un patrimoine culturel de premier ordre. Voix et Images, 30(3), 9-10. https://doi.org/10.7202/011852ar d'utilisation que vous pouvez consulter en ligne.

https://apropos.erudit.org/fr/usagers/politique-dutilisation/ 


\title{
U N PATRIMOINE C ULTUREL DE PREMIER ORDRE
}

\author{
$+++$ \\ ZILÁ BERND \\ Université fédérale du Rio Grande do Sul (Brésil)
}

Mon immersion dans la culture québécoise a commencé en 1980 et, dès le début, j'ai constaté que le grand obstacle à l'introduction de la culture et de la littérature québécoises dans les milieux universitaires brésiliens serait la bibliographie. Comment se procurer dans les années 1980, sans l'aide des technologies que nous avons aujourd'hui (ordinateurs, courrier électronique, Internet, et j'en passe), les livres, manuels et revues à propos de la littérature québécoise, instruments de travail indispensables pour l'enseignement et la recherche?

Quelques années plus tard, vers 1984, quand nous avons pu commencer au Brésil à inscrire la littérature québécoise dans nos programmes d'études françaises des premier et deuxième cycles, j'ai pris connaissance, grâce aux collègues du Département d'études littéraires de l'Université du Québec à Montréal, de Voix et Images - littérature québécoise. Pouvoir compter au Brésil, à plus de 9000 kilomètres de distance du Québec, sur une revue spécialisée en littérature québécoise a contribué de façon décisive à la réussite de notre initiative d'étudier le Québec et sa littérature dans les universités brésiliennes.

La qualité des articles, le soin des éditions et le projet éditorial de proposer des numéros portant sur des écrivains nous ont permis de nous lancer dans l'étude d'auteurs pour lesquels nous ne disposions quasiment pas de ressources bibliographiques. Les dossiers d'auteurs étaient si bien préparés qu'ils sont devenus une source incontournable de référence pour les professeurs et les étudiants universitaires brésiliens. Certains étudiants ont été encouragés à poursuivre un projet de maîtrise après avoir pris contact avec un de ces numéros qui ouvraient les perspectives à différentes approches critiques.

Nous pouvons donc dire, sans exagération, que des revues comme Voix et Images, Vice Versa, Études littéraires, Lettres québécoises et Études françaises sont devenues des éléments indispensables de nos cours et ont assuré la poursuite de notre aventure francophone, étant donné l'impossibilité d'acheter des ouvrages critiques, en raison des difficultés d'importation et des prix élevés (pour notre réalité brésilienne) du transport.

Ceux qui ont la chance d'avoir la collection complète de Voix et Images disposent d'un patrimoine culturel de premier ordre en regard de la grande diversité 
de thèmes et du soin apporté à construire des dossiers spéciaux sur presque tous les écrivains et écrivaines du Québec, sans oublier les essayistes et les questions cruciales de théorie et de critique littéraires, indispensables pour mener à bien l'enseignement de la littérature québécoise.

Ce fut avec une très grande satisfaction que j'ai collaboré à la revue en soumettant des articles: en 1986, j'ai eu l'honneur de participer à un numéro spécial sur l'Amérique latine; en 1999, j'ai écrit une étude sur l'œuvre de Noël Audet, le comparant à des écrivains brésiliens, afin de souligner des éléments d'américanité dans les ouvrages analysés et, en 2000, en collaboration avec Maria Bernadette Porto, j'ai fait la chronique des «Vingt ans d'études québécoises au Brésil».

De lectrice à collaboratrice et correspondante de Voix et Images à partir de 1999, ma relation avec la revue est des plus intimes, si l'on peut dire, étant donné qu'elle a fait partie intégrante de mon processus d'apprentissage de la culture et de la littérature québécoises. La revue est devenue par la suite un espace de diffusion de la lecture brésilienne des textes québécois à partir de la stimulante perspective comparatiste interaméricaine.

Ma présence comme professeure invitée au Département d'études littéraires m'a permis de connaître personnellement plusieurs collègues qui ont été, à tour de rôle, les directeurs de Voix et Images. Avec certains de ces directeurs, dont Lucie Robert, Louise Dupré, Jean-François Chassay et Lori Saint-Martin, j'ai développé des relations professionnelles qui se sont transformées par la suite en relations d'amitié. J'ai eu le plaisir de les recevoir à Porto Alegre, au sud du Brésil, à l'occasion des échanges interuniversitaires UFRGS/UFF/UQAM et certains ont pu collaborer à nos publications, consolidant ainsi les solides liens que nous avons su tisser ensemble, entre nos universités et nos pays respectifs.

Je me rappelle les collègues de l'UQAM qui arrivaient à Porto Alegre pour assurer leur séminaire en littérature québécoise en apportant avec eux des exemplaires de Voix et Images: Bernard Andrès, Dominique Garand, Eva Le Grand et Brenda Dunn-Lardeau étaient parmi ces collègues qui arrivaient chez nous avec les dernières parutions de la revue, toujours très bien reçues par nos étudiants.

Les dossiers thématiques de Voix et Images nous ont aidés à mieux saisir l'espace francophone québécois et ce qu'il représente comme ouverture vers la diversité. L'enseignement du français au Brésil a atteint sa maturité avec l'introduction de la dimension culturelle québécoise: les variantes linguistiques, le combat pour l'affirmation identitaire francophone, l'originalité de sa littérature, enrichie par l'entrecroisement des cultures d'origines diverses venues des différentes géographies, fournissent aux étudiants une ambiance unique qui favorise et stimule l'apprentissage. Comprendre ce que signifie vivre en français en Amérique et prendre conscience que le français peut aussi être un outil de communication entre les Américains nous a permis de développer tout un projet basé sur les relations culturelles et littéraires interaméricaines. Le rôle des revues scientifiques en général et de Voix et Images en particulier dans la réussite de ce projet fut d'une importance majeure. 